\title{
Itinerarios de la corporalidad colectiva en la Argentina de la posdictadura*
}

\author{
Itineraries of collective embodiment in post-dictatorship \\ Argentina
}

\author{
Itinerários da corporalidade coletiva na Argentina \\ pós-ditadura
}

\section{Mariela Singer**}

\begin{abstract}
RESUMEN
El objetivo del presente texto es indagar períodos significativos de la corporalidad colectiva en la posdictadura argentina. Por ello, el escrito se centra en tres momentos fundamentales de la historia reciente: el de los años 80 de la apertura democrática; el correspondiente a los años próximos a la crisis de 2001; y el que se inicia en 2015, con la convocatoria hito al primer \#NiUnaMenos, a partir de la cual se replican las manifestaciones feministas en las calles, a la vez que tiende a prestarse mayor atención al cuerpo como territorio político y como instancia de resistencia. El trabajo se basa en un enfoque situado y se orienta a aportar a los estudios respecto de fenómenos significativos en el sur global.
\end{abstract}

Palabras clave: Argentina, corporalidad colectiva, feminismos, posdictadura.

\footnotetext{
* Este artículo expone resultados de mi investigación doctoral, financiada por becas doctorales del Consejo Nacional de Investigaciones Científicas y Técnicas (CONICET), Argentina.

** Argentina. Doctora en Ciencias Sociales por la Universidad de Buenos Aires (UBA). Profesora Adjunta integrante del Circuito de Formación Feminista de la Facultad de Ciencias Sociales (CIRFFEM-UBA). Directora y Coordinadora Académica del Posgrado "Cuerpo, comunicación, estética y política, perspectivas situadas y feministas", dictado por la Facultad de Ciencias Sociales-UBA y avalado por la Subsecretaría de Políticas de Género y Diversidad Sexual del Ministerio de las Mujeres, Políticas de Género y Diversidad Sexual de la Provincia de Buenos Aires. Coordinadora general del "Área Cuerpo y Comunicación. Problemáticas estético-políticas en la producción de subjetividad", Facultad de Ciencias Sociales, UBA. Buenos Aires, Argentina. marielasing@hotmail.com
} 


\begin{abstract}
This text aims to examine significant periods of collective corporeality in post-dictatorship Argentina. For this reason, the paper focuses on three fundamental moments in recent history: the 1980s, the years of transition to democracy; the years around the 2001 crisis, and 2015, with the landmark movement \#NiUnaMenos, from which feminist demonstrations in the streets emerge while the trend becomes that the body receives greater awareness as a political territory and as a sample of resistance. The work is based on a situated approach and aims to contribute to studies on significant phenomena in the global south.
\end{abstract}

\section{RESUMO}

O objetivo do presente texto é questionar períodos significativos da corporalidade coletiva na pós-ditadura argentina. Por isso, o documento se centra em três momentos fundamentais da história recente: os anos 80 da abertura democrática; o período correspondente aos anos próximos à crise de 2001; e aquele que se inicia em 2015, com a histórica convocatória do primeiro protesto \#NiUnaMenos (\#NemUmaMenos, em português), a partir do qual se replicam as manifestações feministas nas ruas, ao mesmo tempo que se tende a prestar mais atenção ao corpo como território político e instância de resistência. $\mathrm{O}$ trabalho se baseia em uma abordagem situada e visa contribuir para os estudos a respeito de fenômenos significativos no sul global.
Keywords: Argentina, collective corporeality, feminisms, postdictatorship.

Palavras-chave: Argentina, corporalidade coletiva, feminismos, pósditadura. 


\section{Introducción}

El objetivo del presente texto es indagar períodos significativos de la corporalidad colectiva en la posdictadura argentina. Con ese propósito, abordo tres momentos fundamentales de la historia local de las últimas décadas: el de los años 80 de la apertura democrática, considerado de irrupción del cuerpo (Longoni, 2011) en la Argentina reciente; el correspondiente a los años próximos a la crisis de 2001, cuando se replican experiencias de encuentro que valorizan la dimensión festivocorporal; y, por último, el que se inicia en 2015, con la convocatoria hito al primer \#NiUnaMenos el 3 de junio de ese año, a partir de la cual se multiplican las manifestaciones feministas en las calles, a la vez que tiende a prestarse mayor atención al cuerpo como territorio político y como instancia de resistencia, en un contexto generalizado de recrudecimiento de las políticas neoliberales a partir de la asunción, ese año, de un nuevo gobierno nacional (presidencia de Mauricio Macri 2015-2019). Los procesos de corporalidad colectiva analizados en este período incluyen hasta marzo de 2020, cuando con la declaración internacional de pandemia se restringen las manifestaciones presenciales en las calles.

Considero que el análisis de los períodos propuestos, en los que conviven procesos postraumáticos y/o de crisis con la dinamización de experiencias festivas, aporta a pensar las maneras de imbricarse de diferentes sensibilidades y procesos en momentos históricos significativos de la Argentina.

El trabajo expone resultados de investigación de mi tesis doctoral, basada en una estrategia metodológica autoetnográfica (Martínez, 2015; Scribano y De Sena, 2009) que combinó entrevistas en profundidad, descripciones autoetnográficas y análisis bibliográfico y documental, entre otras técnicas. En este texto me centro fundamentalmente en el análisis bibliográfico.

El texto asume un enfoque situado y problematiza las divisiones hegemónicas tradicionales que ubican a Latinoamérica como lugar de mera "aplicación" (Richard, 1996, p. 738) de procesos o creaciones foráneas, valorizando la dimensión creativo-productiva de la experimentación local, tanto en lo que hace a modalidades del activismo como a prácticas artísticas y formas de resistencia. En este sentido, el 
presente escrito se orienta a aportar a los estudios sobre fenómenos significativos en el sur global, destacando la potencia productora de prácticas de este territorio a la hora de crear formas estético-políticas, experiencias y conceptos.

\section{Los años 80 de la apertura democrática}

Los años 80 posteriores a la última dictadura argentina (1976-1983) se caracterizan por el despliegue de una heterogeneidad de experiencias de arte-política que comparten como aspecto distintivo un profundo interés por experimentar la corporalidad y el encuentro colectivo, tal como describen diversidad de investigadoras e investigadores (Garbatzky, 2013; Jacoby, 2011; Longoni, 2011; Lucena y Laboureau, 2016).

Con sus políticas y mecanismos represivos, el régimen dictatorial había actuado como un gran dispositivo disciplinario de los cuerpos y del estado de ánimo de la población, logrando asimismo efectos de atomización entre los sujetos. Este clima opresivo, que interrumpió experiencias de exploración y encuentro que venían desarrollándose en la década del 60 y principios de la del 70, obró a la vez como suerte de "olla a presión" que, con el declive del gobierno dictatorial a principios de los años 80, desató una profunda avidez por experimentar con la corporalidad como instancia de resistencia. Así, se manifestó con fuerza en este período la inquietud por indisciplinar los cuerpos de la normativización intensificada durante la dictadura y por dinamizar encuentros corporales colectivos, tanto en experiencias políticas como artísticas. Como sintetiza Adrián Scribano (2009a), “los 80 se caracterizan por una ruptura del patrón autovigilante impuesto por la dictadura" (p. 2).

De ese modo, la puesta en juego del cuerpo constituye un aspecto distintivo del clima cultural, artístico y político de la apertura democrática y de la efervescencia artístico-experimental de esos años (así como de los últimos años de la dictadura), que se manifiesta en multiplicidad de experiencias de poesía, música, teatro, danza y artes visuales en el espacio público y en centros artísticos de la contracultura porteña.

En esos años se despliegan al menos dos estrategias nítidas orientadas a recuperar las potencialidades del cuerpo frente al aniquilamiento y al disciplinamiento dictatoriales (Jacoby, 2011): la vinculada a las 
Madres de Plaza de Mayo" que se resume en la iniciativa del "Siluetazo"; y la correspondiente a las "estrategias de la alegría", designación acuñada por el artista e investigador Roberto Jacoby (2011) que es utilizada con recurrencia en la literatura sobre arte y política en la Argentina reciente (Amigo, 2008; Longoni 2011; Lucena y Laboureau, 2016).

La iniciativa del Siluetazo surge de tres artistas visuales (Rodolfo Aguerreberry, Julio Flores y Guillermo Kexel) que propusieron a las Madres implementar el recurso masivamente en la III Marcha de la Resistencia ${ }^{2}$, el 21 de septiembre (día nacional del estudiante) de 1983, aún durante la dictadura. La propuesta consistía en empapelar el espacio público con siluetas humanas de tamaño natural para dar cuenta de forma visual de la dimensión de las y los miles de desaparecidos en dictadura. Las siluetas eran confeccionadas a partir de un dispositivo artístico callejero que convocaba a personas comunes a poner su propio cuerpo para hacer visibles los cuerpos ausentes. El procedimiento se basaba en el trazado de la forma vacía de un cuerpo a partir de la figura de las y los participantes, que se acostaban sobre un papel para que fuera dibujado su contorno físico. Las siluetas fueron luego pegadas de forma vertical sobre los muros de la ciudad, en paredes, monumentos, edificios y árboles. Esta actitud estética se basó "en reinventar un 'cuerpo político' mediante la identificación del militante actual que 'ponía el cuerpo' para hacer presente el cuerpo ausente del desaparecido" (Amigo, 2008, pp. 8-9).

1 Madres de Plaza de Mayo es una asociación argentina formada en 1977, durante la última dictadura militar, con el fin de recuperar con vida a las y los detenidos desaparecidos a lo largo de la misma. Se concentró asimismo posteriormente en establecer las responsabilidades de los crímenes de lesa humanidad y de promover su enjuiciamiento. 2 Las marchas de la resistencia son manifestaciones anuales organizadas desde 1981 por las organizaciones de Madres y Abuelas de Plaza de Mayo en la Argentina. 
Figura 1

Paredes de Buenos Aires empapeladas con las imágenes de figuras ausentes de desaparecidas y desaparecidos

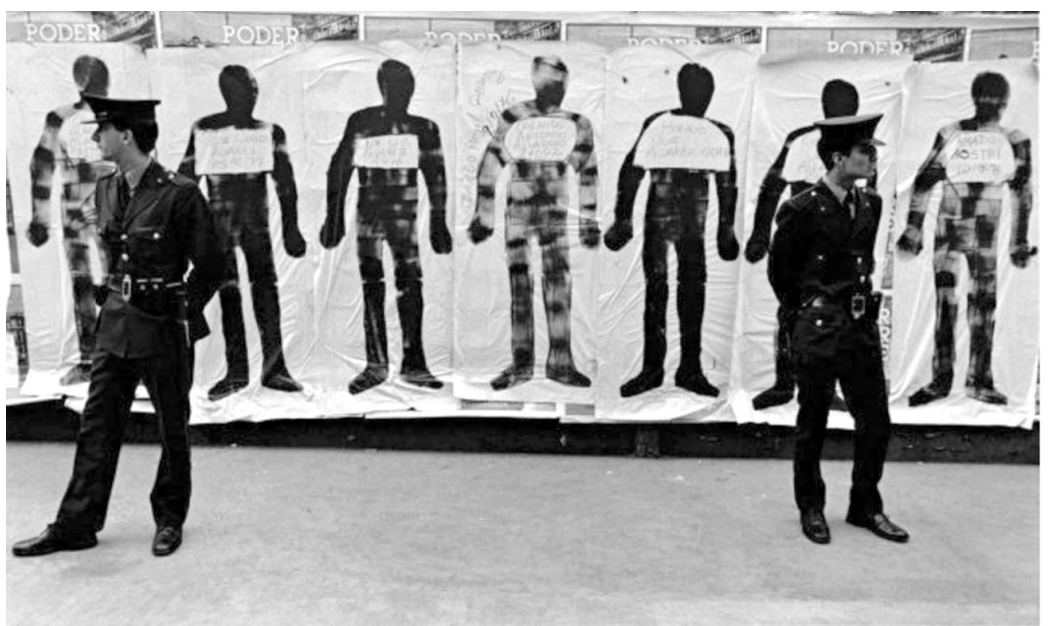

Fuente: Eduardo Gil (1983).

Figura 2

Jóvenes pintando siluetas en el Obelisco durante el Siluetazo

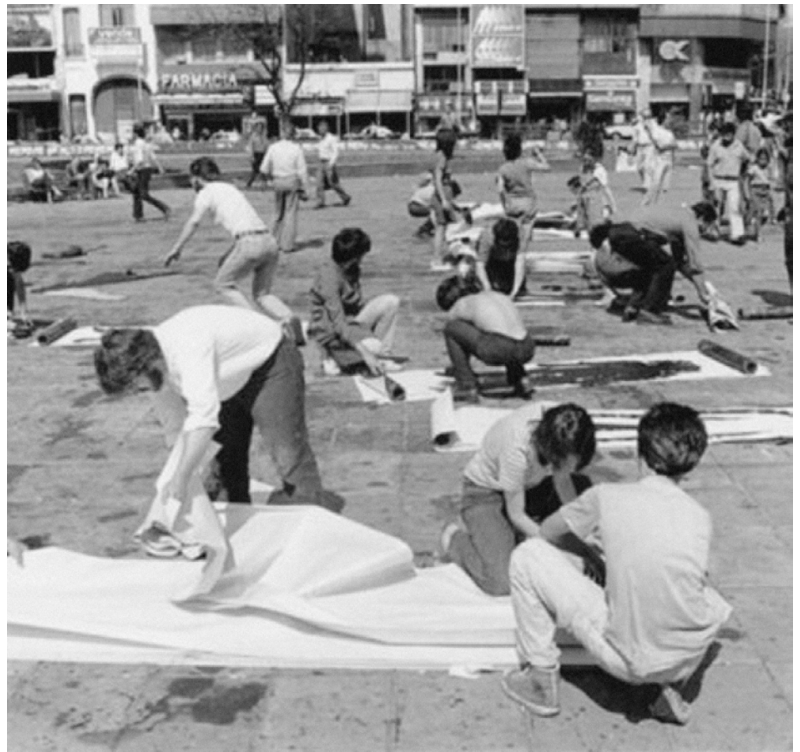

Fuente: Archivo Hasenberg-Quaretti. Colección Centro de Estudios Legales y Sociales. Archivo fotográfico Memoria Abierta (1983). 
La estrategia de la alegría, en tanto, constituye la otra orientación de las prácticas vinculadas a la corporalidad en la posdictadura, y en ella concentra sus reflexiones Jacoby (2011):

Puede describirse de manera muy simple como el intento de recuperar el estado de ánimo a través de acciones asociadas a la música, hacer de ellas una forma de la resistencia molecular y generar una territorialidad propia, intermitente y difusa. (p. 411)

Emergente de manera incipiente a fines de los años 70 durante la última dictadura y continuada y profundizada en la década siguiente, la estrategia referida se basa en la creación de otra sociabilidad, de otra relación con el propio cuerpo y los otros; en la liberación sexual y en el uso de la corporalidad como soporte de experimentaciones artísticas. Surge inicialmente en el ámbito de la música ${ }^{3}$, pero involucra también intervenciones poéticas, teatrales y visuales; acciones con la escenografía; la experimentación con el vestuario y la caracterización con maquillaje; la creación de espacios ficcionales; y la intensificación de prácticas de movimiento y danza, destacándose "la importancia otorgada al baile y al movimiento libre o experimental del cuerpo y las dimensiones lúdicas o carnavalescas del encuentro social" (Jacoby, 2011, p. 411).

La investigadora Ana Longoni (2011) subraya que por entonces, en variados circuitos contraculturales se produce una transformación de la experiencia de participar en un recital de rock: de la escucha del público sentado en sus butacas, al socavamiento de la dinámica estática para dar lugar al baile y al movimiento conjunto. Asimismo, señala que la acción misma de bailar con otras y otros, durante y con posterioridad al gobierno dictatorial, se vivenciaba como un gesto político revulsivo.

También Roberto Amigo (2008) rescata la importancia del baile como forma política de resistencia que atraviesa fuertemente los años 80 , sobre todo al finalizar la dictadura. Bajo la designación de "festiva", este investigador concede gran relevancia a la estrategia de la alegría tematizada por Jacoby:

3 La estrategia de la alegría surge vinculada a la música de rock. Jacoby reconoce como pioneros de este movimiento exploratorio al grupo de rock Los Redonditos de Ricota, quienes en 1977 cambian la disposición de la platea y la relación entre artistas y público, además de disfrazarse y maquillarse, entre otras acciones precursoras. 
La actitud estética festiva es de fuerte impacto durante todos los ochenta y es el núcleo central de la práctica estético-política cotidiana. La recuperación del cuerpo como alegría, como vínculo con el otro - que también podía darse en el ritual de la movilización urbana- era en los años ochenta una demanda política de enorme intensidad: ante el fin de un poder que se había establecido sobre cuerpos torturados y desaparecidos, se danzaba. (Amigo, 2008, pp. $9-10$, cursivas en original)

Frente al terror y al disciplinamiento ejercido durante el régimen dictatorial, orientado a sustraer la potencialidad de los cuerpos, en los años 80 se despliegan y reproducen acciones en una dimensión molecular que llenan el cuerpo de otro tipo de afectos. Esa multiplicidad de acciones festivas surgida en Buenos Aires durante los años 80 constituyó una forma política de resistencia y de confrontación orientada a restituir el lazo social quebrado por el terror, a partir de formas de sociabilidad contrastantes con las propulsadas en el régimen. En este sentido, la socióloga Daniela Lucena (2013) acentúa sobre esos años:

Arte, cuerpo y política se conjugan de un modo inédito para generar momentos festivos, de disfrute y de encuentro colectivo, en contrapunto con la modalidad disciplinadora del cuerpo y el efecto atomista sobre la ciudadanía y la vida social generado por la dictadura. (p. 4)

Asimismo, en esos años de exploración se generan gestos micropolíticos de ruptura con la sexualidad reglamentada y con las identidades normativas de género. A partir de prácticas vestimentarias, maquillaje y conductas corporales, se parodian y cuestionan los tradicionales binarismos sexogenéricos y se experimentan otras posibilidades. Estas acciones estético-políticas del retorno democrático intensificaron la presencia del cuerpo como modo de confrontación con el régimen y construyeron una sociabilidad que resultaba disidente en tanto colocaba en primer plano las posibilidades de goce del cuerpo. Por otro lado, si diversas acciones de performance encontraban un anclaje corporal, fabricaban a la vez corporalidades no preexistentes: la de clowntravesti-literario/a, la niña-dark, el cuerpo títere, entre otros; abriendo nuevos repertorios corporales y modos de aparición del cuerpo (Garbatzky, 2013). 
Así, las exploraciones vestimentarias, las acciones humorísticas, la realización de fiestas, el absurdo y el goce corporal eran parte de los gestos micropolíticos que visibilizaban otras posibilidades frente al estado de ánimo inducido por el régimen dictatorial. Si el cuerpo era objeto de disciplinamiento en la normatividad dictatorial, las corporalidades y prácticas disidentes de los 80 resultaban especialmente revulsivas. Lorena Verzero (2016) subraya al respecto:

De modo desafiante, en los años 80, el cuerpo sexuado irrumpe de la mano de feminismos, travestismos y demás minorías en pugna por su visibilidad. La materialidad de esos cuerpos se enfrenta, a su vez, a los cuerpos desaparecidos. Los cuerpos de los años 80 son los cuerpos desnudos y extasiados, orgiásticos, gozosos, dionisíacos, que estallan en carcajadas, beben, se tocan y bailan, que conviven con cuerpos deformes, raros, espurios, como los cuerpos mutilados de los soldados que volvieron de Malvinas, de las mujeres en lucha por la igualdad de género, de los enfermos de Sida impugnados moralmente. Todos estos cuerpos, a veces incluso ocupados por los mismos individuos, eran igualmente marginados y marginales, sospechados de conductas desobedientes y señalados como objeto de disciplinamiento. (pp. 16-17)

A la vez, la dictadura había significado una interrupción de voces feministas que en los años 80 encuentran un suelo más amplio para desplegarse. Cabe subrayar al respecto la importancia de la experiencia del exilio, el retorno de las exiliadas en esos años y los tráficos de saberes producidos en relación con las vivencias en territorios extranjeros. María Laura Rosa (2014) especifica en este sentido sobre el activismo feminista:

El régimen criminal impuesto por el golpe de 1976 obligó al exilio de un gran número de personas. Las feministas iniciaron, entonces, su silenciamiento, el que irá concluyendo hacia 1980, cuando los primeros indicios de debilitamiento del régimen les permitan nuevamente reunirse. El regreso de las exiliadas, ya en democracia, alimentó la efervescencia de los reencuentros. (p. 19)

También Adriana Barenstein, que en los años 80 de apertura democrática estuvo a cargo de una de las iniciativas artísticas más importantes del Centro Cultural Rector Ricardo Rojas (centro hito de la contracultura porteña de ese período) relaciona su actividad en dicha 
institución con la experiencia de retorno del exilio de un grupo importante de artistas y con el tráfico de saberes propio de aquellos años:

Yo estaba organizando lo que se conocía en ese momento como la movida de Danza Teatro de la UBA. En realidad, la idea era hacer una movida posdictadura: era lo primero que aparecía en democracia, entonces había realmente entusiasmo y ganas de que aparecieran cosas que habían estado muy tapadas. Ese lugar fue un polo al que venía mucha gente que se había tenido que exiliar o que había estado afuera en la época de la dictadura, y muchos volvían con nuevos saberes, o con noticias del Imperio. (comunicación personal, 13 de enero de 2015)

Desde mediados de la década del 80 comienza a realizarse también en la Argentina el entonces Encuentro Nacional de Mujeres, actualmente denominado Encuentro Plurinacional de Mujeres, Lesbianas, Trans, Travestis y No Binaries. Estos encuentros, de realización anual, se inician puntualmente en el año 1986, en pleno contexto de efervescencia activista de la apertura democrática, cuyo espíritu creador de nuevas formas y experiencias se manifestó también en la militancia feminista.

Desde la primera convocatoria, en la que participaron aproximadamente mil mujeres de distintas provincias y ciudades del país en un intercambio en Buenos Aires, los encuentros referidos constituyen un hito del feminismo local (e internacional), en el que se reúnen consecutivamente cada año, de forma ininterrumpida hasta el período previo a la pandemia, un número cada vez mayor de activistas, llegando a participar medio millón de personas en su última implementación presencial, en el encuentro número 34 de la Ciudad de La Plata, Provincia de Buenos Aires, de 2019.

Volviendo a la cuestión de los años 80: el gesto de desobediencia, creación de ámbitos y experiencias de encuentro de entonces involucra la corporalidad de diversas formas. En esa década se multiplican los espacios en los que se ponen en juego prácticas de fuga de subjetividades moralizantes, así como acciones de visibilización de la disidencia y de cuerpos que rompen con configuraciones identitarias normativas. Como destaca Longoni (2011) sobre las experiencias de los años 80:

El cuerpo aparece en estas experiencias como territorio de insubordinación política, al poner en cuestión los regímenes normalizado- 
res y disciplinarios interiorizados, "hechos carne". Estas experiencias están problematizando un orden disciplinario que ha calado muy hondo y modelado las subjetividades. El indisciplinamiento de los cuerpos se manifiesta en términos de una disidencia sexual, que también es política, al poner en cuestión las asignaciones de género y sexuales heteronormativas, e incluso de ciertos corsés "homonormativos". Cuerpos danzantes, en movimiento, travestidos, imprevisibles, el baile colectivo y sin pautas, la fiesta, el desfile improvisado, provocan devenires de los cuerpos que desarticulan cualquier identidad estable. (p. 20)

\section{Los años próximos a la crisis de 2001. Exploraciones estéticas y encuentros corporales festivos}

Si la década del 80 se encuentra signada por una profunda exploración con la corporalidad y por la expansión de experiencias estético-políticas, la década del 90 resulta más ambigua en este sentido.

Por un lado, la profundización del modelo neoliberal de esos años, en un contexto de estabilidad cambiaria en el país (con la "convertibilidad" - paridad entre un peso argentino y un dólar estadounidenseestablecida por ley durante el gobierno de Carlos Menem), sostenida a costa de privatizaciones y de un aumento exponencial de la deuda externa; sumado a la promoción de prácticas consumistas y sus respectivos efectos en las subjetividades, aplacó en parte el espíritu explorador y activista de los años 80 (aun cuando hacia la segunda mitad de los 90 no dejaron de desarrollarse experiencias significativas en el terreno militante y artístico, aumentando hacia fines de la década la conflictividad y protesta social) (Auyero, 2002; Giarraca, 2002).

Por otro lado, en relación con la corporalidad, si bien el período de los años 80 no estuvo exento de tintes sombríos, especialmente si se tiene en cuenta la irrupción del VIH en esos años, la extensión de casos y las muertes acontecidas por Sida afectaron sobre todo el terreno local entre inicios y mediados de la década del 90 (Lemus, 2020). El investigador Francisco Lemus plantea en este sentido que, en correspondencia con la política neoliberal del menemismo, la emergencia del VIH transformó los lazos sociales y las formas de gobernar los cuerpos. Asimismo, la cobertura mediática del virus entrecruzó saberes científicos y no científicos y removió mitos homofóbicos y discursos 
moralizantes. De este modo, la aparición del virus se mostró como un signo asociado a la condición vulnerable de los cuerpos en esa época (Lemus, 2020).

También Roberto Jacoby remarca los efectos de retraimiento que generó el VIH en torno a la cuestión de la corporalidad. En diálogo con Lucena y Laboureau (2008), estas lo interrogan sobre cómo observa la cuestión del cuerpo en los años 90 y Jacoby responde que la cantidad de muertes por Sida en esos años es determinante a la hora de pensar la corporalidad.

Luego de ese retraimiento que atraviesa los años 90, hacia fines de la década y los primeros años 2000, con los sucesos vinculados al "2001 argentino" como punto álgido, se inicia un nuevo proceso de intensificación de la puesta en juego del cuerpo (Di Filippo, 2019; Scribano, 2009a).

Cabe especificar que los sucesos del "2001 argentino" refieren a las jornadas del 19 y 20 de diciembre de ese año, cuando la insurrección popular de miles de manifestantes colmó las calles en diversos puntos de la Argentina al ritmo de cacerolazos y al grito de " $\mathrm{QQue}$ se vayan todos [los gobernantes]!". Los días previos a diciembre de ese año, que confluyeron en el estallido del 19 y 20, incluyeron saqueos y cortes de ruta en varios lugares del país ante el "corralito" financiero anunciado por el entonces ministro de economía Domingo Cavallo, en el momento de mayor crisis de la "convertibilidad", que consistía en impedir a la población retirar su propio dinero y ahorros de los bancos, según el objetivo oficial de detener corridas bancarias. La fuga de capitales de grandes inversionistas y la paralela restricción a la población para extraer su dinero de los bancos, el malestar generalizado, la crisis financiera y la crisis de representación política; potenció la insatisfacción y condujo al derribamiento del principal mandatario (Fernando De La Rúa), así como al sucesivo recambio de —en total— cinco presidentes en tan solo dos semanas.

Cuando el 19 de diciembre, luego de la extensión de los saqueos, cortes y movilizaciones los días inmediatamente anteriores, el entonces presidente Fernando de la Rúa decretó el estado de sitio, terminó de desatar el descontento y la insurrección popular, que ocuparía masivamente el espacio público al golpeteo de cacerolas y que provocaría 
su caída al día siguiente, así como la de quienes lo sucedieron en los días posteriores, además de la multiplicación de movilizaciones y convocatorias desde distintos sectores.

Las protestas desatadas en 2001 se inscriben en el contexto de avance feroz y avasallante del neoliberalismo y de la pérdida de derechos durante la década del 90, así como del deterioro de las condiciones de existencia que significó la consagración del modelo para amplios sectores sociales. El fortalecimiento de la apropiación mercantil e intensificación de la explotación de recursos naturales, con la consiguiente depredación de bienes comunes y la erradicación de poblaciones de sus territorios; la disminución del gasto público y el impacto de esa merma en las políticas sociales; la ley de convertibilidad - que anulaba la capacidad del Banco Central de crear dinero potenciando el endeudamiento externo-, el congelamiento y deterioro de los salarios; la privatización de empresas públicas; el modelo fiscal regresivo y el aumento de la presión tributaria; la transferencia del gasto social a las provincias vía la promovida "descentralización"; así como la especulación financiera y la desindustrialización propia de la desregulación y flexibilización económicas, forman parte fundamental del entramado forjado y consolidado durante los años 90 que coadyuvó al desencadenamiento de nuevas tensiones y luchas sociales, a la vez que a pergeñar modos inéditos de atravesarlas.

Las nuevas formas de lucha desplegadas en este marco de ajuste neoliberal y "capitalismo depredatorio" (Scribano, 2009b, p. 88) comienzan a expresarse en las calles ya a inicios de la década - con el "Santiagazo" del año 93, por ejemplo, entre otros episodios-y cobran mayor visibilidad a partir de los años 1996 y 1997, cuando empiezan a multiplicarse los cortes de ruta y las puebladas en diversos puntos del país, con los casos paradigmáticos de las localidades de Cutral Có en Neuquén y las de Gral. Mosconi y Tartagal en Salta.

A los movimientos de desocupados y desocupadas que se gestan en la década como respuesta a la pérdida de empleo y a la pauperización del poder adquisitivo, y a los movimientos campesinos e indígenas forjados básicamente como respuesta a las consecuencias de la reprimarización de la economía y la expansión de la frontera agrícola; se suma la composición de colectivos de trabajadores y trabajadoras que, vía toma de fábricas, se abocan a la recuperación de empresas desmante- 
ladas como producto de las políticas de los 90, para hacerlas funcionar de manera autogestiva. Finalmente, estas nuevas formas de lucha se verían complementadas por el fenómeno de las asambleas barriales, sobre todo con su proliferación a partir de 2001.

Así, el ciclo de protesta vinculado a la crisis de 2001 fue un punto catalizador que nucleó y expresó luchas y formas de acción colectiva que habían ido configurándose en la Argentina en la segunda mitad de la década del 90. De hecho, un componente insoslayable de esos años fue la emergencia de sujetos que comenzaron a activar formas de movilizarse y de organizarse al margen de las tradicionales organizaciones gremiales y sindicales; sujetos que llegaron a protagonizar prácticamente la mitad de las protestas desplegadas durante el año 1999 (Giarraca, 2002). De este modo, el 2001 significó también un punto de inflexión en cuanto a la emergencia de nuevas formas de pensar y practicar la política, que se expresaron en experiencias conformadas en el marco de esos años como las referidas asambleas barriales, movimientos piqueteros y fábricas recuperadas, entre otras (Giarraca, 2002).

Al mismo tiempo, este ciclo configura un nuevo período significativo para la corporalidad colectiva, en tanto se caracteriza por la presencia física en las calles (Scribano y Cabral, 2009; Svampa, 2004), por encuentros intercorporales y por estéticas festivas (Di Filippo, 2019). Si los cuerpos de los 90 son "cuerpos invisibilizados", producto de "los mecanismos de autoculpabilización y de autoadministración de la pobreza" (Scribano, 2009a, pp. 5-6), los años de fines de los 90 y los próximos al 2001, dan forma a una implosión de corporalidades que luchan por visibilizarse en las calles, por dar cuenta de su existencia precarizada y de su disposición activo-contestataria al orden establecido. El modo en que esa existencia se expresa es a través de la corporalidad y el encuentro colectivos, que asumen a su vez modalidades festivas que celebran ese encontrarse de los cuerpos, así como formas carnavalescas y paródicas de criticar a representantes políticos y políticas, incluyendo acciones performáticas y el uso de materialidades diversas y recursos expresivos (desde el armado de puzles o rompecabezas colectivos; la utilización de disfraces e implementación de sketches que emulan el comportamiento de funcionarios y funcionarias; bailes y coreografías colectivas; etc.). Al respecto, Adrián Scribano y Ximena 
Cabral (2009) señalan en relación con las materialidades y acciones estético-políticas desplegadas en 2001 en la provincia de Córdoba, Argentina:

Esas materialidades pretenden "captar la atención", son instrumentos que los sujetos eligen, crean y se apropian para hacerse escuchar dejándose ver. En ese sentido, la acción colectiva misma es una búsqueda de visibilidad, de hacerse notar por parte de los exciudadanos, de los expulsados y expropiados de sus voces y de otras materialidades. Estas expresiones "performadas" posibilitan y necesitan que propios y extraños tomen nota, y así, de forma simultánea, dar con las claves de una gramática de las acciones y geometría de los cuerpos que dejan sin posibilidad de ser vistos, escuchados y reconocidos a millones de sujetos. En este escenario la protesta social puede ser entendida en tanto momento de visibilidad de la acción colectiva y como la externalización de una multiplicidad de redes de conflictos previas; y es en ese tiempo-espacio donde la protesta se vincula con la puesta en escena colectiva a partir de la construcción-selección de recursos expresivos. (p. 131)

En los años inmediatamente posteriores al 2001 emergen experiencias y prácticas estético-políticas en las calles que intensifican la exploración colectiva. De hecho, inmediatamente después de las jornadas de diciembre, en el año 2002, se multiplica la irrupción de grupos de arte-política y la intervención de manifestaciones estéticas en el espacio público (Longoni, 2010; Vázquez, 2008).

Scribano y Cabral (2009) subrayan que "estas protestas se distinguieron por la creatividad con que reconstruyeron y escenificaron las redes conflictuales de las cuales formaban parte" (p. 132). Los cuerpos tomaron las calles como campo de expresión y de performances, y como superficies de inscripción de estéticas heterodoxas. Estas prácticas de las estéticas-en-las-calles (Scribano y Cabral, 2009), más aún, establecieron disputas por la visibilidad y llevaron al desarrollo de dramaturgias renovadas al momento de escenificar conflictos:

La calle se configura como escenario donde emergen prácticas, imágenes y relatos que disputan en el espacio público la representación de la realidad, la "legitimidad" y el poder de dichas representaciones. En la disputa por el poder de representación -repre- 
sentación que configura prácticas-, los colectivos y movimiento sociales van desarrollando estrategias de visibilidad con base en ciertas formas y figuras con las que buscan simbolizar y representar algo más que sus demandas. (pp. 131-132)

De ahí que la dimensión estética y corporal de esas protestas adquirió una relevancia fundamental en "la reconfiguración de las tramas conflictuales". (p. 131)

Es interesante, en ese sentido, que no solo trabajos centrados en Buenos Aires dan cuenta del hito que significó el 2001, sino también periodizaciones que amplían y complejizan las temporalidades porteñas en relación con los ciclos de protesta y que abordan los modos de manifestación de la corporalidad colectiva en diferentes ciudades del país (Di Filippo, 2019, para el caso de Rosario; Pérez Balbi, 2019 para la Ciudad de La Plata; y Scribano, 2008 y Scribano y Cabral, 2009, que hacen foco en la experiencia de Córdoba; entre otros desarrollos). En estas elaboraciones, aún con las periodizaciones específicas y singulares a los diferentes territorios, el 2001 constituye un hito temporal común en el país.

Asimismo, en los años próximos posteriores al 2001, el movimiento de mujeres cobra mayor protagonismo, pronunciando y replicando los encuentros y debates en torno a problemáticas de género, e incorporando esas cuestiones en espacios asamblearios emergentes durante el período de insurrección. Las mujeres se acercan a ponerle el cuerpo a estos espacios en pos de la incorporación de temáticas feministas, entre las que se incluyen la demanda a favor del aborto legal.

Como plantean Jesica Calcagno y María Chaves (2007), a partir de las movilizaciones de diciembre de 2001 las reivindicaciones de las mujeres, que hasta entonces habían quedado acotadas mayormente al espacio de las organizaciones feministas y de mujeres, comienzan a ser incorporadas en las asambleas populares, en los movimientos de desocupadas y desocupados y en los encuentros de fábricas recuperadas.

Por su parte, en cuanto a la cuestión de la corporalidad, corresponde subrayar que el ciclo que transcurre entre 1997 y 2005, con intensificación entre 2001 y 2002, constituye un período en que las resistencias a las políticas neoliberales están marcadas por una revalorización de la presencia física y "por la obligación del aquí y ahora de los cuerpos" (Di Filippo, 2017, p. 2), aspectos que caracterizan a esos años de con- 
flictividad social y de efervescencia popular para luego declinar en el ciclo posterior, de 2005 a 2012, que tiende a una virtualización de la participación.

Scribano (2008) describe ese declive como un "estado de coagulación de la acción colectiva y la sensación de agotamiento de las energías sociales disruptivas", (p. 227), señalando que no implica negar la existencia de protestas y colectivos en lucha, pero sí dar cuenta de la condición de "las cotidianas batallas de los cuerpos" (p. 227) en esos años.

En esa misma dirección, la periodización de Ana Longoni (2011) sobre los activismos artísticos en las últimas décadas especifica que, luego de la rebelión popular de 2001 y de la irrupción en 2002 de diversidad de colectivos de arte politizados, que promovían encuentros corporales colectivos, a partir de 2003 se produce un repliegue de estos activismos, los cuales volverán a potenciarse en el ciclo que se inaugura en el año 2015.

\section{El ciclo 2015-2020. NiUnaMenos, masificación de los feminismos y valorización de la corporalidad}

En cuanto a los últimos años, el ciclo de protesta que comienza en 2015 conforma un nuevo hito de revalorización de la presencia física, de intensificación de manifestaciones de corporalidad colectiva y de mayor interés por la cuestión del cuerpo como territorio político.

La masificación de los feminismos a nivel internacional en los años recientes, en el caso de la Argentina encuentra como punto de inflexión el 2015, cuando el 3 de junio de ese año se realiza la primera movilización de \#NiUnaMenos, que logra una convocatoria multitudinaria en las calles. A partir de entonces, otros hitos fueron dando cuenta de la masificación del movimiento, como el primer paro nacional de mujeres el 19 de octubre de 2016; el primer paro internacional de mujeres el 8 de marzo de 2017 (que se replica en una gran cantidad de ciudades y países, realizándose desde entonces consecutivamente cada 8 de marzo a nivel global); y las manifestaciones masivas por la legalización del aborto a partir de 2018, que colman las calles a lo largo de todo el país. Asimismo, en los últimos años se produce también un aumento considerable de participantes en el (actualmente designado) Encuentro Plurinacional de Mujeres, Lesbianas, Travestis, Trans y No Binaries. 
Figura 3

Activistas a favor del aborto voluntario alzan masivamente sus pañuelos verdes frente al Congreso de Buenos Aires, Argentina, el 19 de febrero de 2020

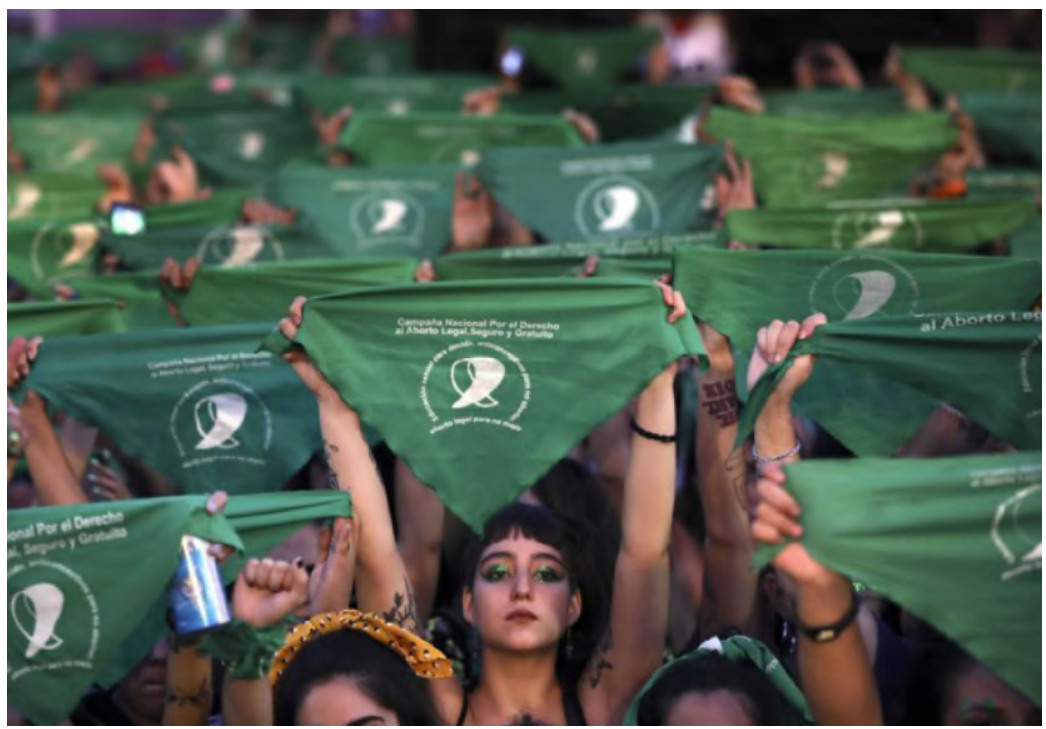

Fuente: Natacha Pisarenko (AP/photo).

En relación con esa expansión de los feminismos, cabe tener en cuenta, como plantea la reconocida pensadora Silvia Federici (2015), que las activistas y teóricas feministas históricamente han jugado un rol fundamental en la valorización del cuerpo, tanto por verlo como una clave para comprender las relaciones de explotación como para pensar la construcción de la identidad social feminizada, y para problematizar la moralización y disciplinamiento de la corporalidad (especialmente las feminizadas y disidentes), entre otros aspectos.

Asimismo, la valorización de la corporalidad constituye un punto fuerte en las perspectivas feministas a la hora de pensar la ocupación de espacios públicos y prácticas asamblearias libradas en diversos territorios. En estas perspectivas, el cuerpo es considerado instancia activa que produce significaciones irreductibles al orden discursivoracional, y no por eso menos tangibles y potentes.

Judith Butler (2017), por ejemplo, destaca la potencia de acción y la fuerza significante de la presencia del cuerpo en la protesta, y del carácter corporeizado del cuestionamiento a parámetros de dominio. De 
hecho, la tesis específica de su libro Cuerpos aliados y lucha política, según ella misma explicita, es que "la acción conjunta puede ser una forma de poner en cuestión a través del cuerpo aspectos imperfectos y poderosos de la política actual" (p. 17).

Según plantea la autora, la unión de los cuerpos en las luchas colectivas genera una potencia de aparición que trasciende el campo de significados discernibles a nivel discursivo y corre umbrales no solo en cuanto al contenido de las demandas, sino respecto de quiénes pueden realizarlas. Los "cuerpos aliados" en la calle o la plaza pública brindan legitimidad y derecho a aparecer a quienes no se suele ver, trastocando umbrales sensibles respecto de a quiénes se les da palabra, e instalando nuevos reclamos a partir de la generación de imágenes y prácticas que conforman problematizaciones en acto, desde los cuerpos. En palabras de Butler (2017):

La propia actuación adquiere entonces otro sentido, por cuanto esas formas corporeizadas de acción y movilidad tienen significado más allá de las palabras (...) La reunión es significativa más allá de lo que en ella se diga, y este modo de significación es una actuación conjunta de los cuerpos, una forma de performatividad plural. (p. 16)

Figura 4

Miles de cuerpos en las calles pronunciándose a favor del aborto voluntario y generando potentes imágenes colectivas. Buenos Aires, Argentina, diciembre de 2020

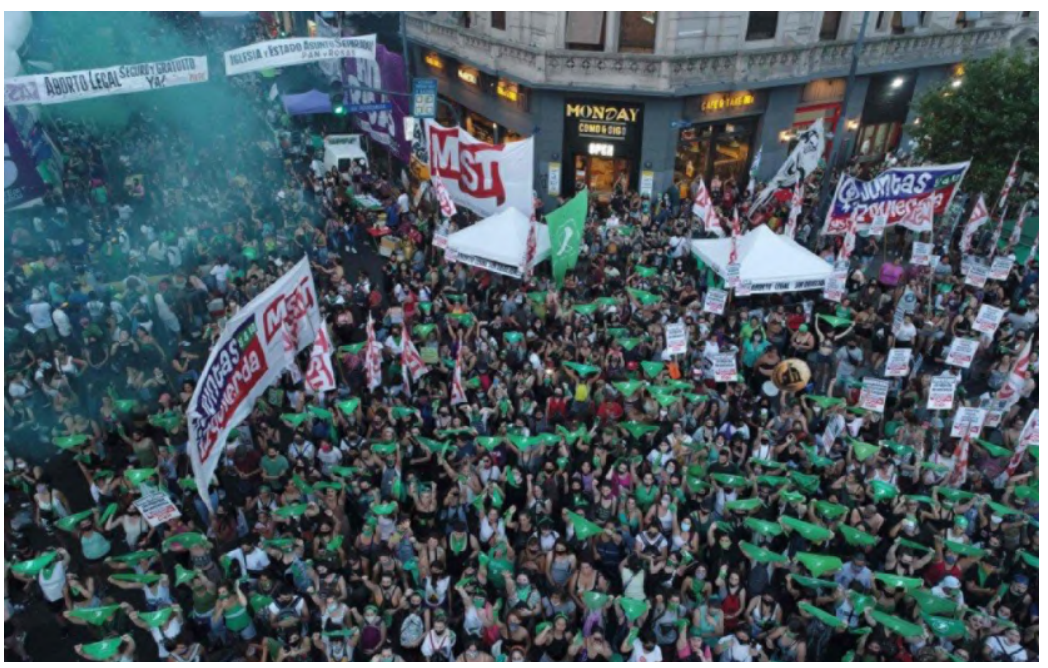

Fuente: Emiliano Lasalvia (AFP), 2020. 
Por su parte, la pensadora feminista argentina Verónica Gago (2019; 2020), destaca la actualidad del movimiento de mujeres lesbianas, trans y travestis, así como la importancia del cuerpo en la lucha feminista y las formas corporeizadas de la protesta social contemporánea.

En ese sentido, si los feminismos históricamente han ejercido un rol significativo en la valorización del cuerpo, promoviendo el pensamiento del cuerpo como territorio político, no es extraño que su masificación y las transformaciones estético-sensibles de los últimos años hayan profundizado el interés por la corporalidad, así como visibilizado la importancia de los encuentros corporales en su dimensión afectiva, estética y política.

La etapa abierta en 2015, en el contexto de un gobierno nacional asumido ese año que tiene como presidente a Mauricio Macri (reconocido empresario de los sectores más poderosos del país); se caracteriza por la multiplicación de las resistencias a las políticas neoliberales y por un nuevo despliegue de manifestaciones estéticas en las calles, tal como señalan estudios de arte y política en la Argentina reciente (De La Puente y Manduca, 2019). Del mismo modo, en este período es significativa la presencia de la corporalidad y la importancia de la dimensión relacional-afectiva de las acciones políticas colectivas (Fuentes, 2019; Vázquez, 2019).

Como plantea Cecilia Vázquez (2019), a partir de compartir colectivamente experiencias estético-políticas en las calles se generan formas de afectividad potentes que operan como redes de comunicación y de cobijo entre pares con una sensibilidad común. La dimensión relacional-afectiva aparece asimismo como uno de los lugares en que se elabora la visibilidad de las multitudes feministas, creando un espacio particular, novedoso, donde surgen modos renovados de relacionarse.

En las escenas callejeras de las manifestaciones, puede observarse la "multiplicación de escenas de abrazos, encuentros, emociones compartidas tanto de alegría, complicidad y disfrute como de frustración, dolor y tristeza" (Vázquez, 2019, p. 12). Estos modos de sociabilidad y afectación mutua potenciados en las protestas de los últimos años dan forma a una politicidad colectiva claramente sostenida en la dimensión sensible-corporal; frecuentemente organizada, por otro lado, en combinación con modalidades de convocatoria a través de las redes 
sociales, que por esos mismos medios dinamizan e intensifican la exhortación a encontrarse entre los cuerpos. Como señala la investigadora Marcela Fuentes (2020):

Para denunciar y enfrentar la violencia de género y el sexismo como fenómenos multidimensionales, las movilizaciones feministas contemporáneas investigan y exploran los recursos que ofrecen tanto las redes sociales como la performance corporalizada. Estos ocupan un lugar protagónico en la creación de narrativas colectivas en la lucha por el significado y el valor de los cuerpos por fuera de los órdenes naturalizados. (pp. 199-200)

Figura 5

Dos manifestantes abrazándose en la calle con emoción y alegría ante la aprobación del proyecto de ley de aborto voluntario en la Cámara de Diputados en la Argentina. Buenos Aires, diciembre de 2020

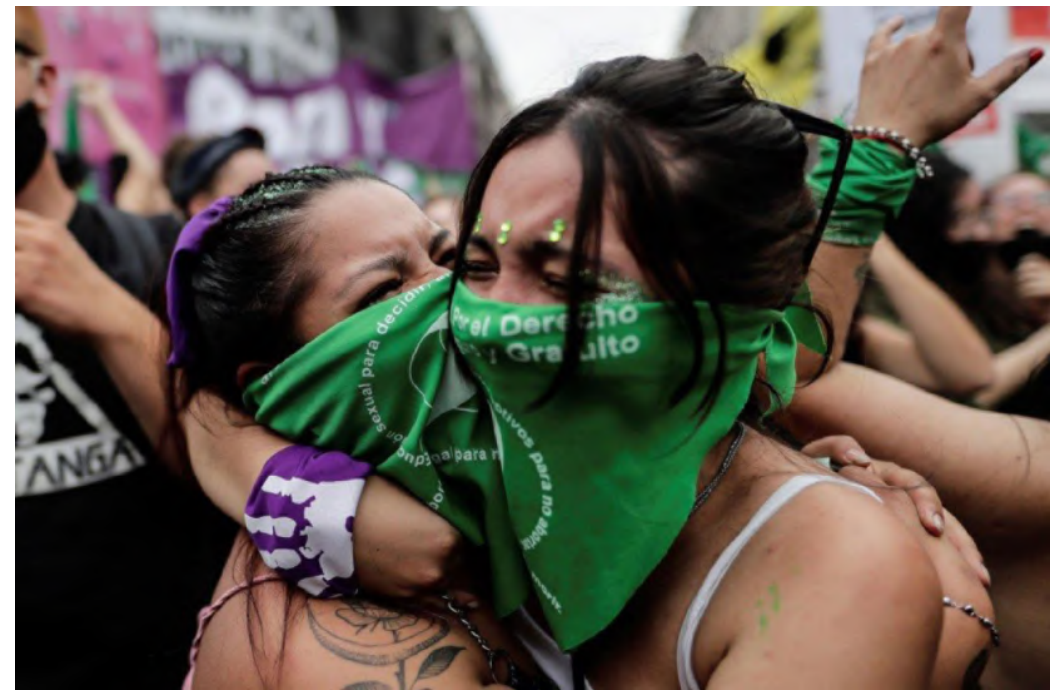

Fuente: Juan Ignacio Roncoroni (EFE), 2020.

En el período abierto en 2015, al igual que en 2001, destaca el carácter festivo y carnavalesco de las puestas en acto de los cuerpos, con una intensificación de los lazos afectivos. Las escenificaciones corporales colectivas, en este caso, incluyen expresiones estéticas tales como inscripciones corporales, cánticos colectivos, utilización de maquillaje y brillo en diferentes zonas del cuerpo, el uso del verde y el violeta como colores distintivos (de la campaña a favor del aborto voluntario y del 
movimiento feminista, respectivamente) en prendas de vestir y otro tipo de accesorios, así como el uso de instrumentos de percusión y expresiones de danza. La danza, de hecho, se presenta con fuerza no solo en performances artísticas puntuales, sino también en performances ampliadas de la protesta, en las que el baile y el movimiento colectivo, o incluso las coreografías masivas pautadas, son consideradas instancias de encuentro indisciplinadas que agitan el ánimo alegre de las manifestaciones, contagian a otras personas y fortalecen la lucha (en este sentido, es paradigmático el caso del colectivo de artistas chilenas LASTESIS, cuya coreografía de protesta se ha replicado a nivel internacional). En todo este marco, se multiplican las redes y escenas de afecto (Gago, 2019; 2020; Vázquez, 2019), haciendo de la comunicación entre cuerpos un elemento distintivo de estos repertorios políticos.

Como agrega Vázquez (2019) en relación con el cuerpo individual y colectivo en este período, "la trama de afectos como la complicidad, la voluntad de estar juntas, el placer por el intercambio, el carácter festivo y lúdico van elaborando lo común en cada movilización que se expresa a través de un cuerpo colectivo" (p. 11), a la vez que el conjunto de los elementos referidos indica "la pertenencia a un ritual en el cual se da sentido al cuerpo individual y al colectivo desde apuestas lúdicas y festivas" (p. 2).

En esa dirección, cabe subrayar que la expansión de las luchas feministas viene generando aperturas en los modos de concebir y practicar la política, favoreciendo perspectivas que conceden privilegio a la materialidad de los cuerpos. Diferentes tipos de experiencias en el terreno local e internacional, tanto del activismo militante como de exploración artística, etc., vienen problematizando representaciones normativas de la corporalidad; explicitando un acceso desigual a la ciudadanía marcado en las corporalidades; democratizando regímenes de visibilidad de los cuerpos; a la vez que creando y multiplicando instancias de encuentro e intensificando redes de comunicación entre corporalidades diversas.

Estas luchas y desplazamientos hacia lo corpóreo-sensible (que en los feminismos cobraron impulso hace décadas - por lo menos desde la del 70- y que se actualizan con fuerza en nuestra contemporaneidad local e internacional, especialmente con el enorme crecimiento y fortalecimiento del activismo feminista), suponen una valoración de 
experiencias y prácticas tradicionalmente desdeñadas y confieren profunda politicidad al cuerpo como territorio (no solo de inscripción), sino de transformación del orden social.

En este marco de transformaciones que ha habilitado y profundizado el movimiento feminista, los encuentros y la comunicación desde la corporalidad pueden leerse destacando su enorme politicidad. Del mismo modo, es de acentuarse la ruptura que supone un desplazamiento hacia el cuerpo y hacia el afecto como dimensiones valoradas de la acción política colectiva contemporánea, en contraste con paradigmas tradicionales racionalistas.

\section{Reflexiones finales}

De lo expuesto en este trabajo puede extraerse un conjunto de conclusiones. En primer lugar, los tres períodos abordados (los años 80, el 2001 y el que se inicia en 2015) son períodos de crisis económicas, de recrudecimiento de ajustes o, como en el caso de la década del 80, un momento posdictatorial. Es decir, que comparten el hecho de que las prácticas desplegadas en ellos conviven y tratan de revertir, de una u otra manera, los efectos dramáticos de las políticas neoliberales y represivas sobre los cuerpos.

Por otro lado, entre los tres períodos tematizados puede establecerse un hilo en términos de la importancia dada al cuerpo como instancia de resistencia y a la corporalidad colectiva como forma de encuentro y acción política. Asimismo, la modalidad de esa acción, en los tres contextos, se caracteriza por una ética de la presencia física en las calles y por la dimensión festiva y afectiva del encuentro, que tiende a aumentar la potencia de los cuerpos y la expansión de las luchas o resistencias micropolíticas. Evidentemente, en períodos postraumáticos o de crisis se refuerza la necesidad de encuentros corporales, de desajustar los dispositivos disciplinarios que tienden a moralizar los cuerpos y a restringir sus posibilidades sensibles en lo cotidiano.

Del mismo modo, cabe destacar que los tres períodos constituyen momentos sumamente significativos de la historia argentina reciente, comenzando por los años 80. De hecho, las prácticas disruptivas y de indisciplina corporal forjadas en la apertura democrática como estrategia contestataria y de recomposición frente al disciplinamiento y la 
normalización dictatoriales, fueron labrando un tejido sensible que actualmente puede considerarse "soporte", o suelo subjetivo importante de multiplicidad de experiencias posteriores que han hecho foco en el cuerpo como práctica de resistencia política y de transformación.

Por su parte, el 2001 constituyó un hito de inflexión en términos de encauzar experiencias políticas que trascendían las dinámicas de la democracia representativa y que ponían, en cambio, el foco en el cuerpo y en los encuentros en el espacio público. Finalmente, el ciclo de protesta abierto en 2015 inaugura una revolución sensible que se profundiza y expande de modos impensados, cuyos efectos se muestran claramente irreversibles en lo que hace a su incidencia en las subjetividades, en las corporalidades y en los lazos sociales; con transformaciones que conmueven multiplicidad de terrenos (laborales, cotidianos, domésticos, sindicales, académicos, etc.).

Por otro lado, atendiendo al enfoque situado que propuso este texto, según el cual se problematizan las divisiones hegemónicas que consideran a Latinoamérica como lugar de mera "aplicación" de creaciones foráneas (Richard, 1996, p. 738), me interesa destacar la dimensión creativo-productiva de la experimentación local: la creación de formas y experiencias que constituyen un aporte y una enseñanza para los activismos.

Entre la gran cantidad de experiencias que abarcan los períodos tematizados y que podrían recuperarse, señalo —en pos de abreviarlas siguientes: la creación de los encuentros de mujeres que se realizan anualmente desde los años 80, en tanto fenómeno inédito que convoca en los últimos años a medio millón de personas y que atrae la atención de los feminismos a nivel global; la multiplicidad de prácticas micro y macropolíticas, poéticas, activistas en relación con la demanda de aborto/interrupción voluntaria del embarazo, que ya se había visto reforzada en los años próximos a la crisis de 2001 y que ha incluido en estos últimos años, con fuerza masiva notoria especialmente a partir de 2018, la difusión, circulación y apropiación a nivel internacional del pañuelo verde, como símbolo de una lucha persistente del sur global, así como ha incluido también una diversidad de prácticas creativas que fueron sororamente acompañadas desde una gran cantidad de territorios y que lograron instalarse en la agenda de reivindicaciones del feminismo internacional, fortaleciendo la expansión de la lucha por el 
aborto en otros territorios latinoamericanos o de Abya Yala (para recuperar la designación indígena del continente); y finalmente, de modo más reciente, la creación del paro internacional de mujeres a partir de 2017, como práctica que también se replica témporo-espacialmente y que se fortalece en el feminismo internacional.

En ese sentido, las experiencias y prácticas latinoamericanas dan cuenta de una potencia irreductible y constituyen aportes significativos, inéditos y creativos que amplían la imaginación política del activismo internacional.

Por último, considero que el análisis de los períodos trabajados (en los que conviven procesos postraumáticos y/o de crisis con la dinamización de experiencias festivas) aporta a pensar las maneras de imbricarse de diferentes sensibilidades y procesos en momentos históricos significativos, especialmente en los que la fiesta deviene en estrategia política de resistencia. Al respecto, en el contexto regional de los últimos años, adquiere especial actualidad la necesidad de reflexionar acerca de los complejos modos que puede cobrar la interrelación entre el avance paralelo de la militancia festiva y de políticas neoconservadoras y opresivas. En este sentido, el análisis de los períodos tematizados llevado a cabo en este texto tal vez pueda aportar, de modo general y complementario a los objetivos planteados en este escrito, al abordaje de esa reflexión.

\section{Referencias}

Amigo, R. (2008). 80 / 90 / 80. Revista Ramona, 1(87), 8-14. http://70.32.114.117/gsdl/collect/revista/revistas/ ramona87.pdf

Auyero, J. (2002). Fuego y barricadas. Retratos de la beligerancia popular en la Argentina democrática. Revista Nueva Sociedad, 1(179), 143-162. https://nuso.org/articulo/fuegoy-barricadas-retratos-de-la-beligerancia-popular-en-laargentina-democratica/

Butler, J. (2017). Cuerpos aliados y lucha política. Hacia una teoría performativa de la asamblea. Paidós.

Calcagno, J. y Chaves, M. (5-9 de noviembre de 2007). La lucha por el derecho al aborto en Argentina desde 2001 hasta 2007: de la combatividad en las calles a la pasivización. VII Jornadas 
de Sociología. Universidad de Buenos Aires. https://cdsa. aacademica.org/000-106/355.pdf

De la Puente, M. y Manduca, R. (27-28 de marzo de 2019). Memorias que invaden la ciudad, cuerpos que la actúan. Jornadas de Arte y Memoria. Centro Cultural Paco Urondo, Universidad de Buenos Aires. http://pacourondo.filo.uba.ar/sites/ pacourondo.filo.uba.ar/files/Programa\%20\%281\%29.pdf

Di Filippo, M. (28-30 de septiembre de 2017). Transfiguraciones en la corporalidad estético-política: de la fiesta a la necroteatralidad. Un análisis en torno a los repertorios de protesta por Franco Casco y Jonatan Herrera. Rosario (2014-2017). X Seminario Internacional Políticas de la Memoria, Buenos Aires, Argentina. http://conti.derhuman.jus.gov.ar/2018/01/ seminario/mesa_25/difilippo_mesa_25.pdf

Di Filippo, M. (2019). Estéticas políticas:activismoartístico, movimientos sociales y protestas populares en la Rosario del nuevo milenio. Ediciones Universidad Nacional de Rosario.

Federici, S. (2015). Calibán y la bruja. Mujeres, cuerpo y acumulación originaria. Tinta Limón.

Fuentes, M. (2019). \#NiUnaMenos: Performances activistas y performatividad de los hashtags contra la violencia de género. En A. G. Altynay, M. J. Contreras, M. Hirsch, J. Howard, B. Karaca, y A. Solomon (Eds.), Women Mobilizing Memory (pp. 172-191). Columbia University Press.

Fuentes, M. (2020). Activismos tecnopolíticos. Constelaciones de performance. Eterna Cadencia Editora.

Gago, V. (2019). La potencia feminista. O el deseo de cambiarlo todo. Tinta Limón.

Gago, V. (2020). Lecturas sobre feminismo y neoliberalismo. Revista Nueva Sociedad, 1(290). https://nuso.org/articulo/lecturassobre-feminismo-y-neoliberalismo/

Garbatzky, I. (2013). Los ochenta recienvivos; poesía y performance en el Río de la Plata. Beatriz Viterbo editora.

Giarraca, N. (2002). Argentina 1991-2001: Una década de protesta que finaliza en un comienzo. La mirada desde el país interior. Revista Argumentos, 1(1), 1-8. https://dialnet.unirioja.es/ descarga/articulo/3991598.pdf 
Gil, E. (1983). Siluetas y canas. Siluetazo [imagen]. https://www. eduardogil.com/siluetazo.html\#\&gid=1\&pid=10

Hasenberg, M. y Quaretti, B. (1983). Jóvenes pintando siluetas en el Obelisco durante el Siluetazo [imagen]. Archivo HasenbergQuaretti. Colección Centro de Estudios Legales y Sociales. Archivo fotográfico Memoria Abierta. https://www.macba. cat/es/exposiciones-actividades/actividades/estrategiascreativas-movimiento-derechos-humanos-argentina

Jacoby, R. (2011). La alegría como estrategia. En A. Longoni (Ed.), $E l$ deseo nace del derrumbe. Roberto Jacoby, acciones, conceptos, escritos (pp. 410-412). La Central-Adriana Hidalgo editoraMuseo Nacional Centro de Arte Reina Sofía, MNCARS.

Lasalvia, E. (2020). Manifestación a favor del aborto afuera del Congreso en Buenos Aires [imagen]. AFP/Getty images. https:// cnnespanol.cnn.com/2020/12/11/camara-de-diputadosde-argentina-aprueba-ley-de-acceso-a-la-interrupciondel-embarazo-voluntario/

Lemus, F. (2020). Llegó el Sida. Revista de Estudios y Políticas de género, 1(4), 66-84. https://revistas.untref.edu.ar/index.php/ ellugar/article/view/790/688

Longoni, A. (2010). Tres coyunturas del activismo artístico en la última década. Poéticas contemporáneas. Itinerarios en las artes visuales en la Argentina de los 90 al 2010. Fondo Nacional de las Artes.

Longoni, A. (Ed.) (2011). Introducción. El deseo nace del derrumbe. Roberto Jacoby. Acciones, conceptos, escritos (pp. 5-27). La Central-Adriana Hidalgo editora-Museo Nacional Centro de Arte Reina Sofía, MNCARS.

Lucena, D. (2013). Guaridas underground para dionisos. Prácticas estético-políticas durante la última dictadura militar y los años 80 en Buenos Aires. Asry. Arte y Sociedad. Revista de Investigación (4) https://www.eumed.net/rev/ays/4/index. html

Lucena, D. y Laboureau, G. (2008). Cuestiones de amor y de muerte. Contextos anacrónicos del arte (1968-2008). Revista Ramona, 1(87), 39-44. http://70.32.114.117/gsdl/collect/ revista/revistas/ramona87.pdf 
Lucena, D. y Laboureau, G. (2016). Modo mata moda. Arte, cuerpo y (micro)política en los 80. Ediciones Edulp, Editorial de la Universidad Nacional de La Plata.

Martínez, A. (2015). Una reflexión autoetnográfica sobre la práctica de las artes marciales de contacto: ser una (uno) entre todos ellos. Revista Astrolabio, (14), 290-312. http://ediciones. ucsh.cl/index.php/TSUCSH/about/submissions

Pérez Balbi, M. I. (2019). Habitar/confabular/crear. Activismo artístico en La Plata. Ediciones Edulp, Editorial de la Universidad Nacional de La Plata.

Pisarenko, N. (2020). Miles de activistas por el aborto legal alzan sus icónicos pañuelos verdes y se manifiestan a favor de la despenalización frente al Congreso en Buenos Aires [imagen]. AP/photo. https://www.hrw.org/es/news/2021/11/02/asies-como-las-mujeres-latinoamericanas-podemos-seguirluchando-por-el-derecho-al

Richard, N. (1996). Feminismo, experiencia y representación. Revista Iberoamericana, 62(176-177), pp. 733-744. https://doi. org/10.5195/reviberoamer.1996.6256

Roncoroni, J. I. (2020). Dos mujeres muestran su alegría en las calles de Buenos Aires después de que la Cámara de Diputados de Argentina aprobara el proyecto de ley para legalizar el aborto. (EFE), 2020. https://efeminista.com/argentinaaborto-legal-aprobacion-camara-diputados/

Rosa, M. L. (2014). Legados de libertad. El arte feminista en la efervescencia democrática. Editorial Biblos.

Scribano, A. (2008). Sensaciones, conflicto y cuerpo en Argentina después del 2001. Espacio Abierto. Cuaderno Venezolano de Sociología. 17(2), 205-230. https://ri.conicet.gov.ar/ bitstream/handle/11336/29626/CONICET_Digital_ Nro.5e6de4ee-1674-4570-a3fa-72abdd38b2b9_X. pdf? sequence $=5$ \&isAllowed $=\mathrm{y}$

Scribano, A. (2009a). Una periodización intempestiva de las políticas de los cuerpos y las emociones en la Argentina reciente. Boletín Onteaiken, (7), 1-12. http://onteaiken.com.ar/ver/ boletin7\%20(1)/1-1.pdf

Scribano, A. (2009b). Acciones colectivas, movimientos y protesta social: preguntas y desafíos. Revista Conflicto Social, 2(1), 
86-117. http://biblioteca.clacso.edu.ar/Argentina/iigguba/20140723024203/0105_scribano.pdf

Scribano, A. y Cabral, X. (2009). Política de las expresiones heterodoxas: el conflicto social en los escenarios de las crisis argentinas. Convergencia. Revista de Ciencias Sociales, (51), 129-155. http://www.scielo.org.mx/scielo.php?script=sci_arttext\&pi $\mathrm{d}=\mathrm{S} 1405-14352009000300006$

Scribano, A. y De Sena, A. (2009). Construcción de conocimiento en Latinoamérica: Algunas reflexiones desde la autoetnografía como estrategia de investigación. Revista Cinta de moebio (34), 1-15. https://scielo.conicyt.cl/scielo.php?pid=S0717554X2009000100001\&script=sci_abstract

Svampa, M. (2004). Relaciones peligrosas. Sobre clases medias, gobierno peronista y movimientos piqueteros. Revista $\mathrm{El}$ Rodaballo, 1(15), 1-16. http://www.maristellasvampa.net/ archivos/ensayo02.pdf

Vázquez, C. (2008). Arte y protesta: notas sobre prácticas estéticas de oposición. En P. Alabarces y M. C. Rodríguez (Comps.). Resistencias y mediaciones. Estudios sobre cultura popular. Paidós.

Vázquez, C. (16-18 de octubre de 2019). Las multitudes feministas en el espacio público: estéticas, afectos y política. XXI Congreso de la Red de Carreras de Comunicación Social y Periodismo. Universidad Nacional de Salta, Salta, Argentina.

Verzero, L. (2016). Prólogo. Cuerpos irreverentes: los años 80 más contraculturales que nunca. En D. Lucena y G. Laboureau (Eds.), Modo mata moda. Arte, cuerpo y (micro)política en los 80. Ediciones Edulp, Editorial de la Universidad Nacional de La Plata. 